Research Article

\title{
Experimental Study on the Seismic Behaviour of Reinforced Concrete Bridge Piers Strengthened by BFRP Sheets
}

\author{
Yong Li, ${ }^{1,2}$ Meng-Fei Xie $\mathbb{D}^{1},{ }^{1}$ and Jing-Bo Liu ${ }^{2}$ \\ ${ }^{1}$ The Key Laboratory of Roads and Railway Engineering Safety Control, Shijiazhuang Tiedao University, \\ Shijiazhuang 050043, China \\ ${ }^{2}$ Department of Civil Engineering, Tsinghua University, Beijing 100084, China \\ Correspondence should be addressed to Meng-Fei Xie; xiemengfei@126.com
}

Received 7 January 2019; Revised 11 May 2019; Accepted 18 June 2019; Published 1 July 2019

Academic Editor: Chiara Bedon

Copyright (c) 2019 Yong Li et al. This is an open access article distributed under the Creative Commons Attribution License, which permits unrestricted use, distribution, and reproduction in any medium, provided the original work is properly cited.

\begin{abstract}
With the continuous development of the ductility capacity concept for seismic design of bridges, the ductility capacity of many existing bridges does not meet the requirements of the current code for seismic performance because of the low reinforcement ratio and reinforcement corrosion of reinforced concrete $(\mathrm{RC})$ piers. Because of their superior mechanical properties and low price, basalt fibre-reinforced polymer (BFRP) sheets have potential application in the seismic retrofits field of existing bridges. To study the seismic strengthening effect of RC pier columns, scaled specimens with standard reinforcement ratios, with low reinforcement ratios according to the past code and with corroded reinforcements, were designed and manufactured and then wrapped and pasted with BFRP sheets on the plastic hinge areas. Pseudostatic tests were conducted to verify the seismic performance of the strengthened and unstrengthened specimens. Experimental results showed that the ultimate flexural capacity, deformation capacity, and energy dissipation capacity of strengthened RC pier columns were superior. Especially for strengthened specimens with low reinforcement ratios or corrosion reinforcement, their seismic performance could rival than that of columns with standard reinforcement ratios, which showed the advantage of BFRP sheets in the seismic retrofitting of existing bridge piers.
\end{abstract}

\section{Introduction}

Bridge damage in earthquakes leads to traffic interruption and economic losses [1]. At present, there are a large number of viaducts designed according to the elastic seismic design method adopted by the previous seismic design code for highway bridges [2]. After Wenchuan earthquake of 2008, the seismic design code for bridges [3] adopted the ductility seismic design concept which recommends two-stage design and twolevel fortification. Additionally, the newest Seismic Ground Motion Parameter Zonation Map of China (GB 18306-2015) increased the areas of seismic fortification intensity of $7^{\circ}$ and above and put forward the concept of very rare ground motion [4]. Therefore, bridges in service designed according to the previous seismic design code cannot meet the seismic performance objects of the current seismic design code.

Reinforced concrete (RC) piers of existing viaducts would bear various loads and might also be subjected to the marine environment or severe atmospheric conditions. Chemical erosion always causes corrosion and mechanical degradation of reinforcements, which affects the usability and safety of the structures. When corroded RC piers are subjected to earthquakes, serious damage or even collapse may occur. Aseismic design is adopted to prevent bridge collapse and control seismic damage to a certain extent. At present, the seismic concept design combining elastic superstructure and ductile substructure is used mostly in the seismic design of bridges $[5,6]$. Plastic hinges can appear in certain positions of RC pier columns to realize the ductility seismic design $[7,8]$. Therefore, reinforced concrete piers with insufficient flexural ability or ductility ability, unclear plastic hinge positions, or clear positions that are hard to repair need to be retrofitted.

Many studies have been carried out on the seismic reinforcement of viaduct piers with fibre-reinforced polymer (FRP) sheets $[9,10]$. At present, commonly used fibres include aramid fibre-reinforced polymer (AFRP), glass fibrereinforced polymer (GFRP), and carbon fibre-reinforced polymer (CFRP), and CFRP is the most widely used material 
because of its excellent properties $[11,12]$. However, CFRP is largely imported in China, and its high cost restricts the application. Compared with other FRPs, basalt fibre-reinforced polymer (BFRP) shows a series of good mechanics performance, as shown in Table 1. More importantly, BFRP is derived from natural minerals and worthy to be spread, with advantages of low cost and nonpollution [13, 14].

There are few studies on the application of BFRP sheets in the seismic strengthening of building and bridge structures. $\mathrm{Lu}$ et al. [15-17] conducted a study on the seismic performance of earthquake-damaged concrete frame joints reinforced by BFRP sheets. The results showed that the seismic performance of strengthened joints was greatly improved, and all 3-dimensional reinforced concrete frame joints strengthened by BFRP sheets achieved the design object of strong-column and weak-beam. $\mathrm{Wu}$ et al. [18] conducted a contrastive study of strengthened short RC columns with BFRP bundles (not BFRP sheets) and CFRP sheets. It was recommended that BFRP bundles can significantly improve the shear capacity and change the failure mode of short RC columns. Because there is less research on BFRP sheets used in seismic strengthening of viaduct piers, quasistatic loading tests of 1:5 scaled pier columns were conducted under low-cycle reciprocating loading to obtain the hysteresis performance curve, and then stiffness, flexural capacity, equivalent viscous damping coefficient, and energy dissipation parameters were analysed to reveal the improvement efficiency of BFRP sheets in seismic strengthening.

\section{Experimental Design}

2.1. Specimen Design and Fabrication. Five scaled specimens of circular RC pier columns, $2100 \mathrm{~mm}$ high and $240 \mathrm{~mm}$ diameter, were designed and fabricated. Two specimens were designed with standard reinforcement ratios and one of them was strengthened; one specimen was designed with lower reinforcement ratio and strengthened; and two specimens were designed with standard reinforcement ratios and corroded and one of them was strengthened. The geometric dimensions and reinforcement details of specimens are shown in Figure 1. The tested cubic compressive strength of concrete was $43.2 \mathrm{MPa}$. Longitudinal reinforcement included hot-rolled ribbed steel bars $10 \mathrm{~mm}$ in diameter, and the tested yield strength was 498.3 MPa. Stirrup bars adopted hot-rolled plain steel bars $8 \mathrm{~mm}$ in diameter, and the tested yield strength was $358.3 \mathrm{MPa}$.

2.2. Corrosion and Strength of Specimens. A flume filled with $\mathrm{NaCl}$ solution at a concentration of $3.5 \%$ was set up in the plastic hinge area of two specimens. Stainless steel tubes were placed in the flume as electrochemical cathodes, and one longitudinal steel bar extending through the top of specimens served as electrochemical anodes. The concentration and volume of the $\mathrm{NaCl}$ solution remained unchanged during the electrifying process $[19,20]$. The designed density was determined to be $0.6 \mathrm{~mA} / \mathrm{cm}^{2}$ according to Faraday's formula. Details of the corrosion specimens are listed in Table 2, and the electrification process is shown in Figure 2. At the end of corrosion process, both the corroded longitudinal and stirrup steel bars showed pitting corrosion. The actual corrosion rate was evaluated by the cross-section method. The tested diameters of longitudinal and stirrup steel bars were $9.8 \mathrm{~mm}$ and $7.1 \mathrm{~mm}$, respectively. The yield strengths of longitudinal and stirrup steel bars were 309.2 $\mathrm{MPa}$ and 281.4 MPa, respectively.

Mechanical properties of the BFRP sheets used for strengthening are shown in Table 3. First, the surface of specimens was polished and smoothed, and then the BFRP sheets coated with adhesive were wrapped and adhered to the specimens. The adhesive was XW-500-A carbon fibre, and the colloidal properties are listed in Table 4. To avoid damage in the lap areas, the lap length was set at $100 \mathrm{~mm}$. One layer of the BFRP sheet was wrapped vertically in the tensile direction, and two layers were wrapped laterally. The adhesion height of each layer was set at $400 \mathrm{~mm}$.

\subsection{Measuring Points Arrangement and Loading System.} Four strain gauges were symmetrically pasted on longitudinal steel bars located on both sides of each specimen. Two strain gauges were pasted on two stirrup bars on one side of the specimen. Four concrete strain gauges were pasted on both sides of each specimen. Four displacement sensors were laterally installed on both sides of the specimen. Another displacement sensor was set up at the top of specimen to measure the lateral deformation of the specimen top. The details of measuring points are shown in Figure 3.

According to the seismic design code [3], the axial compression ratio of regular viaducts should not exceed 0.3. Therefore, the axial compression ratio was set 0.2 during tests. Throughout tests, the vertical load of $146.0 \mathrm{kN}$ was applied at the top of specimens and kept constant. Lateral reciprocating loads were applied to the specimen top, as shown in Figure 4(a). A loading rule of variable amplitude displacement control was adopted to conduct the pseudostatic tests (Figure 4(b)). Testing ended when the lateral bearing capacity of the specimen decreased by $85 \%$ of the maximum value or when the specimen was destroyed [21].

The dynamic response of the structural components under seismic loads is partly different from the pseudostatic tests, because of the different Young's Moduli of concrete when it is exposed to quasistatic loads rather than dynamic excitation [22]. However, quasistatic tests can effectively obtain the mechanical properties of structural members, thus providing technical support for the research of the structural resilience model and structural failure mechanism and mode.

\section{Experimental Results}

3.1. Failure Characteristics of Columns. As shown in Figure 5, failure characteristics of the strengthened and unstrengthened specimens under quasistatic loading were different. At the initial loading stage, lateral cracks appeared at the plastic hinge area of unstrengthened columns. With the increase in loading, lateral cracks gradually extended and widened. Finally, concrete at the plastic hinge area crushed and the column failed. For the corroded specimen, there were vertical and lateral corrosion cracks with a width of $0.05-0.15 \mathrm{~mm}$ before loading (Figure 2(d)). In the initial 
TABLE 1: Comparison of different FRPs.

\begin{tabular}{lcccc}
\hline Type & Tensile strength $(\mathrm{MPa})$ & Elastic modulus $(\mathrm{GPa})$ & Maximum elongation $(\%)$ & Suitable temperature $\left({ }^{\circ} \mathrm{C}\right)$ \\
\hline BFRP & $3000-4800$ & $80-110$ & 3.30 & $-200-650$ \\
GFRP & $3100-4650$ & $73-86$ & 5.20 & $-60-350$ \\
CFRP & $3500-6000$ & $230-250$ & 2.20 & $-100-500$ \\
AFRP & $2900-3400$ & $70-140$ & 3.60 & $-60-250$ \\
\hline
\end{tabular}

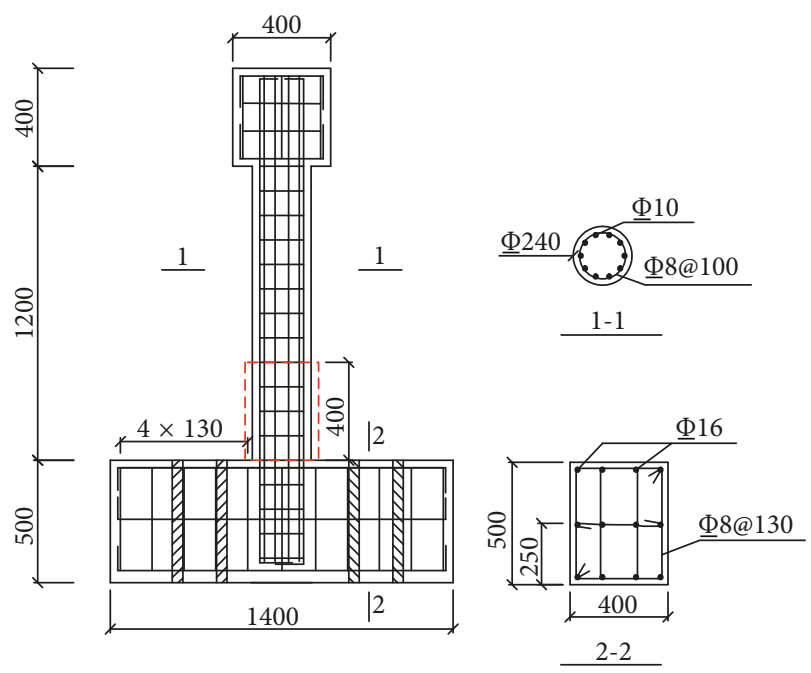

(a)

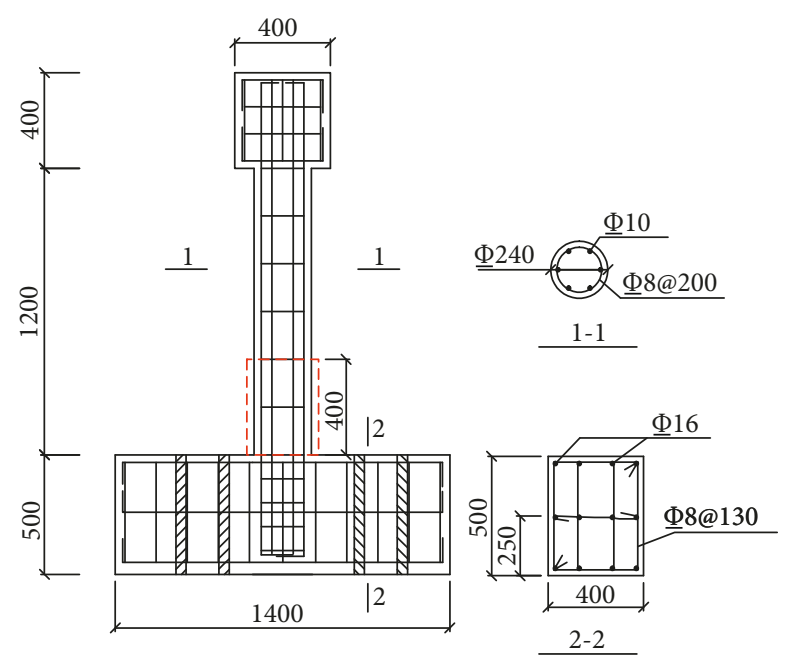

(b)

FIGURE 1: Details of specimens: (a) standard reinforcement ratio; (b) low reinforcement ratio (unit: mm).

TABLE 2: Design parameters of specimens.

\begin{tabular}{lcccccc}
\hline Numbering & $\begin{array}{c}\text { Theoretical } \\
\text { corrosion rate (\%) }\end{array}$ & $\begin{array}{c}\text { Actual corrosion } \\
\text { rate (\%) }\end{array}$ & $\begin{array}{c}\text { Longitudinal } \\
\text { reinforcement ratio (\%) }\end{array}$ & $\begin{array}{c}\text { Volume stirrup } \\
\text { ratio (\%) }\end{array}$ & $\begin{array}{c}\text { Strengthened by } \\
\text { BFRP sheets }\end{array}$ & $\begin{array}{c}\text { Axial } \\
\text { pressure ratio }\end{array}$ \\
\hline NU-1 & - & - & - & 1.7 & 1.0 & No \\
NU-2 & - & - & 1.7 & 1.0 & 0.2 \\
LU-2 & - & 7.3 & 1.1 & 0.5 & Yes & Yes \\
NC-1 & 8.0 & 7.2 & 1.7 & 1.0 & No & 0.2 \\
NC-2 & 8.0 & 1.0 & 0.2 & Yes \\
\hline
\end{tabular}

1, unstrengthened; 2, strengthened; C, low reinforcement ratio; N, standard reinforcement ratio; $\mathrm{U}$, uncorroded.

stage of lateral loading, corrosion cracks extended and new cracks appeared gradually. As the lateral load continued to increase, corrosion cracks elongated and widened and more lateral cracks developed. Finally, concrete in the plastic hinge area was crushed, concrete between the corrosion cracks fell off, and the column specimen failed.

For specimens strengthened by BFRP sheets, a slight crackling sound could be heard from the surface of the BFRP sheets in the initial stage of lateral loading, which was caused by a slight fracture between the sheets and the colloid. At the same time, lateral cracks appeared above the reinforced area. As the lateral load continued to increase, lateral cracks in the unstrengthened area above the strengthened area gradually extended and then cracks appeared in the connection between the column bottom and the base. Finally, the cracking failure appeared at the connection between the column and the cap, whereas the plastic hinge area strengthened by BFRP sheets remained in a good condition.
3.2. Hysteresis Curve. The load displacement curves of reinforced concrete columns are drawn according to the lateral load and displacement of the specimen top, as shown in Figure 6.

It can be seen in Figure 6 that the reinforcement ratio, steel corrosion, and BFRP sheets all affect the energy dissipation of specimens. The hysteresis loop area, flexural capacity, and ultimate displacement of the unstrengthened specimen NU-1 were smaller than those of the strengthened specimen NU-2. Under multidirectional forces including lateral loads and axial pressure, BFRP sheets delayed the creation and expansion of cracks in the plastic hinge area and thus delayed concrete failure. In addition, the strengthened specimen LU-2, with a low reinforcement ratio, showed an equivalent hysteresis loop area and flexural capacity with the unreinforced column NU-1, with a standard reinforcement ratio.

When the steel bars in specimen NC-1 were corroded, the flexural capacity and ductility of the specimen were 


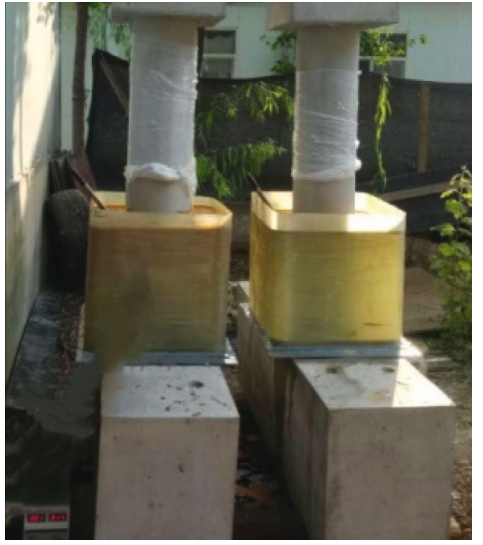

(a)

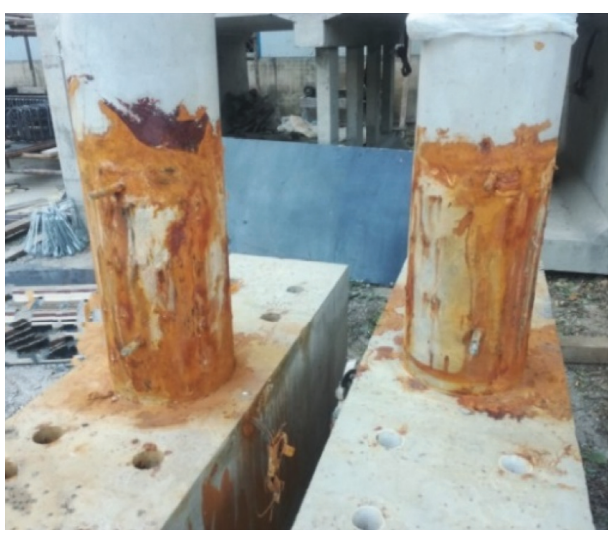

(c)

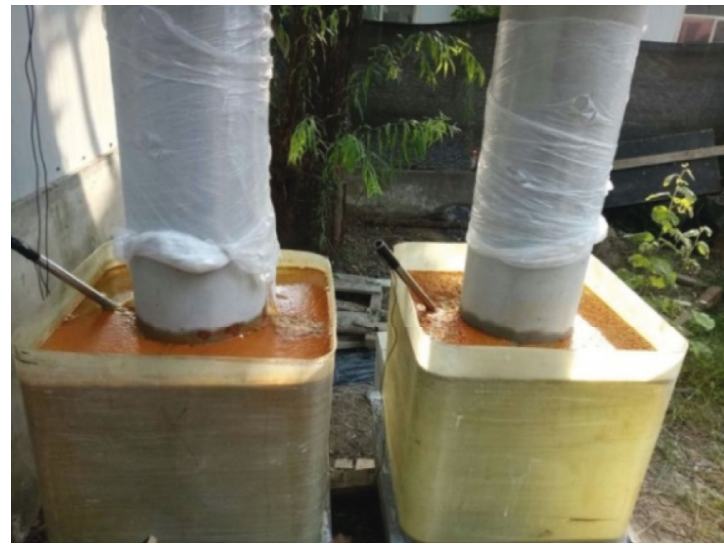

(b)

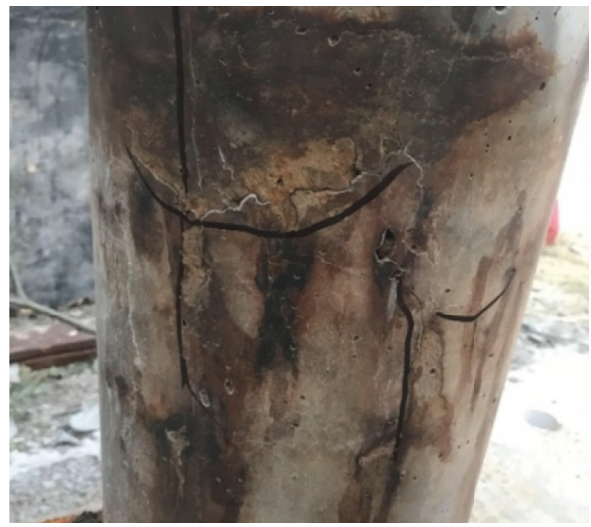

(d)

FIGURE 2: Corrosion of specimens: (a) beginning; (b) during corrosion; (c) after corrosion; (d) corroded crack.

TABLE 3: Mechanical properties of BFRP sheets.

\begin{tabular}{lccc}
\hline Mass density $\left(\mathrm{kg} / \mathrm{m}^{3}\right)$ & Tensile strength $(\mathrm{MPa})$ & Elastic modulus $(\mathrm{GPa})$ & Elongation at break $(\%)$ \\
\hline 3000 & 3200 & 105 & 2.6 \\
\hline
\end{tabular}

TABLE 4: Colloidal properties of carbon fibre adhesive.

\begin{tabular}{lllll}
\hline Tensile strength $(\mathrm{MPa})$ & Elastic modulus $(\mathrm{MPa})$ & Elongation at break (\%) & Bending strength (MPa) & Compressive strength (MPa)
\end{tabular}

$\geq 40$ $\geq 2500$ $\geq 1.5$ $\geq 50$ $\geq 70$

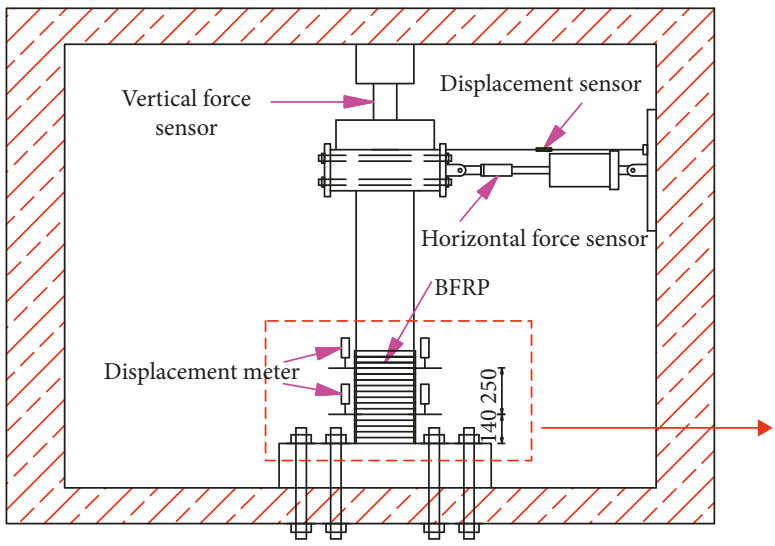

(a)

(b)

FIGURE 3: Measuring points arrangement: (a) deformation measuring points; (b) strain measuring points (unit: mm). 


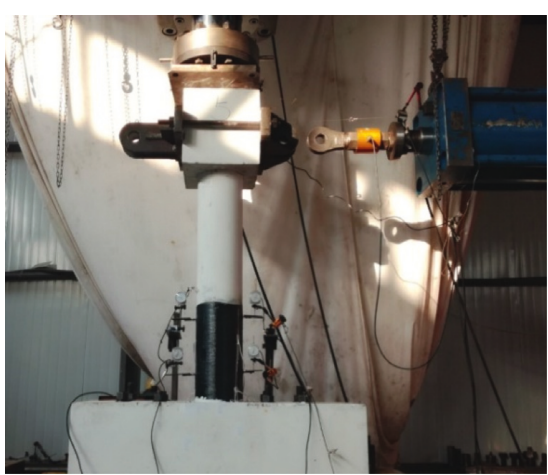

(a)

(b)

FIGURE 4: Loading system: (a) test devices; (b) actual lateral displacement applied.

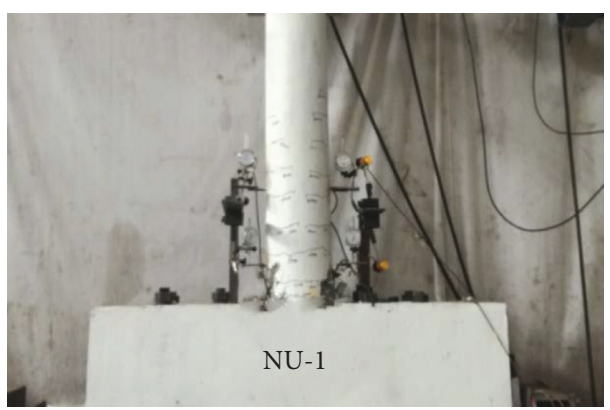

(a)

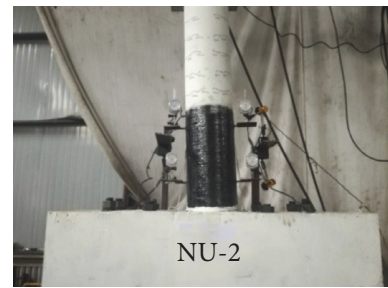

(c)

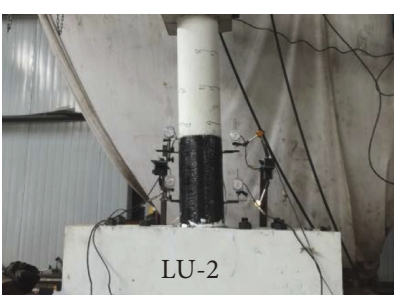

(d)

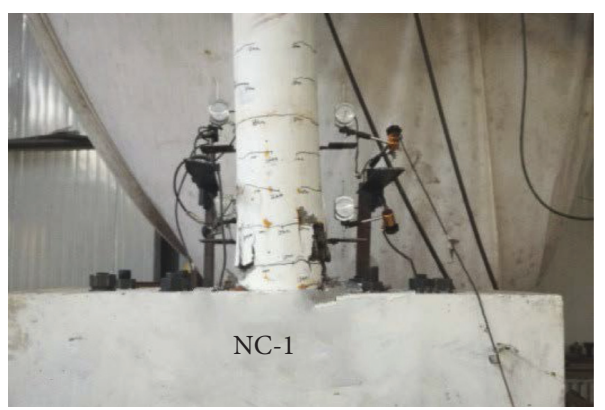

(b)

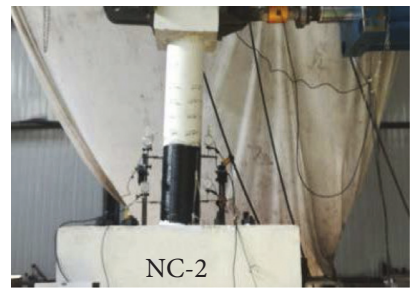

(e)

Figure 5: Failure characteristics of specimens:

(a) NU-1; (b) NC-1 (c) NU-2; (d) LU-2; (e) NC-2.

reduced to a certain extent (Figure 6(d)). After the BFRP sheet strengthened the corroded column, it restrained the lateral expansion of concrete, limited the extension and widening of corrosion cracks, and delayed concrete failure. As a result, the ultimate flexural capacity of the corroded specimen NC-2 was higher than that of unstrengthened specimen NC-1, and the ultimate displacement also greatly increased.

3.3. Strain Analysis. The strain of the longitudinal steel bars, stirrups, and BFRP sheets of specimens are shown in Figure 7.

As can be seen in Figure 7, under the same conditions, the reinforcement strain of the strengthened specimen is lower than that of the unstrengthened specimen. At the same time, the yield strain and ultimate strain of the strengthened specimen are both delayed compared with those of the unstrengthened specimen. In Figure 7(c), S-1 and S-2, respectively, represent the vertical strain on the basalt fibre sheet surface $140 \mathrm{~mm}$ and $390 \mathrm{~mm}$ from the bottom of specimen. It can be seen in the figure that the vertical strain of the BFRP sheet increases rapidly after the steel reaches yield no matter where it is.

3.4. Skeleton Curves. The skeleton curves of specimens were obtained according to the tested hysteretic performance curves, as shown in Figure 8. Furthermore, yield load $F_{\mathrm{y}}$, peak load $F_{\mathrm{p}}$, ultimate load $F_{\mathrm{u}}$, and corresponding drift ratios $\theta_{\mathrm{y}}, \theta_{\mathrm{p}}$, and $\theta_{\mathrm{u}}$ as well as ductility coefficient $\mu$ can be obtained and are shown in Table 5 . Ductility coefficient $\mu$ reflects the ductility of reinforced concrete columns and can be calculated according to the following formula:

$$
\left\{\begin{array}{l}
\mu=\theta_{\mathrm{u}} / \theta_{\mathrm{y}}, \\
\theta_{\mathrm{u}}=\Delta_{\mathrm{u}} / l, \\
\theta_{\mathrm{y}}=\Delta_{\mathrm{y}} / l,
\end{array}\right.
$$

where $\Delta_{\mathrm{y}}$ and $\Delta_{\mathrm{u}}$ represent the top displacement of columns at the stage of longitudinal bars yielding and the stage when 


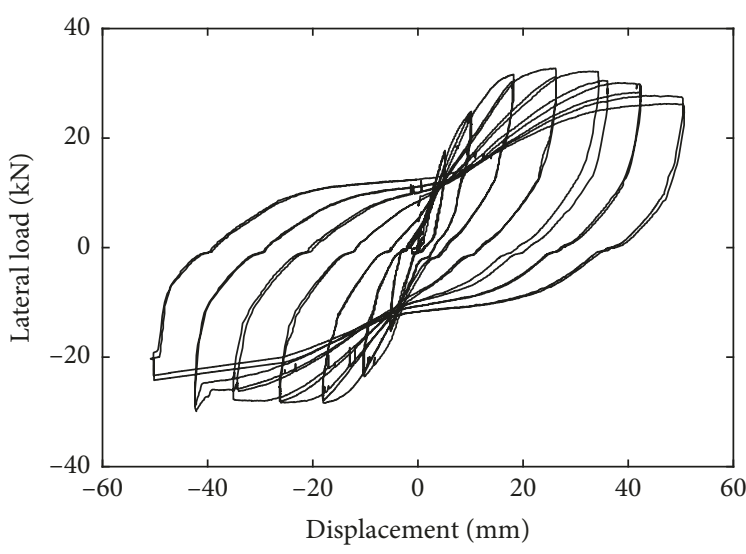

(a)

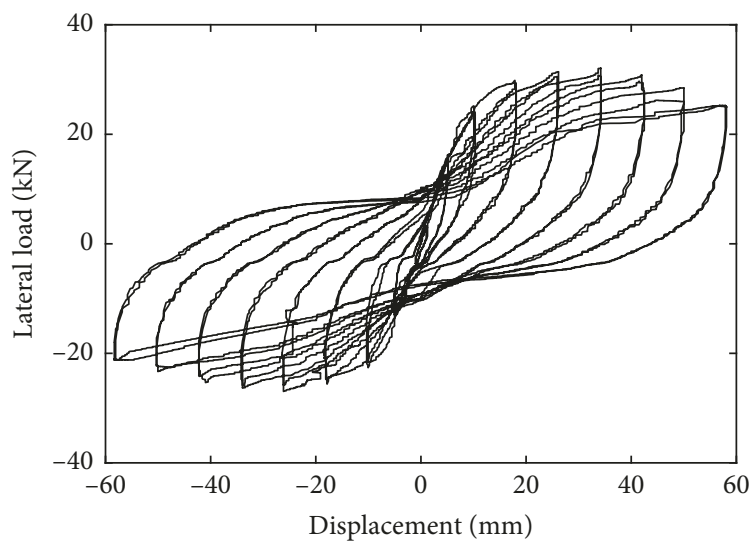

(c)

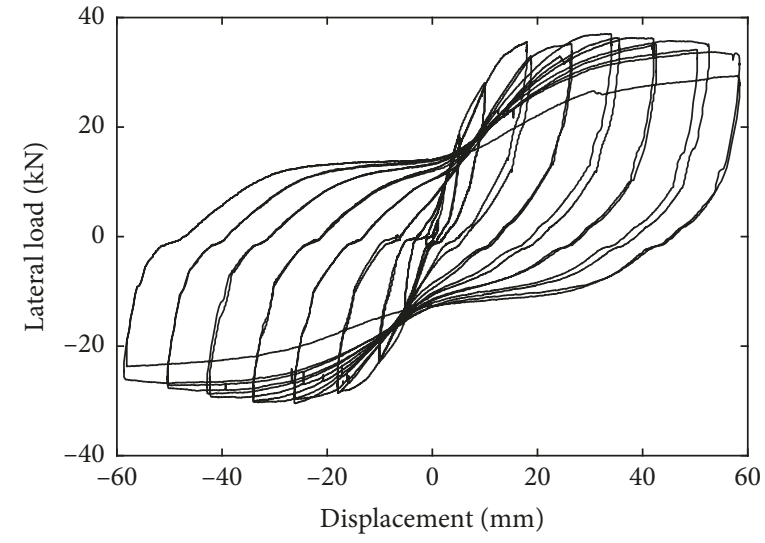

(b)

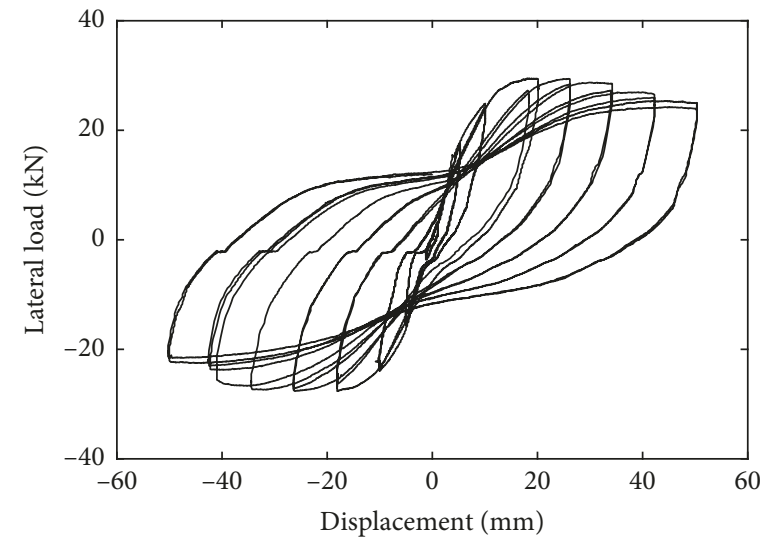

(d)

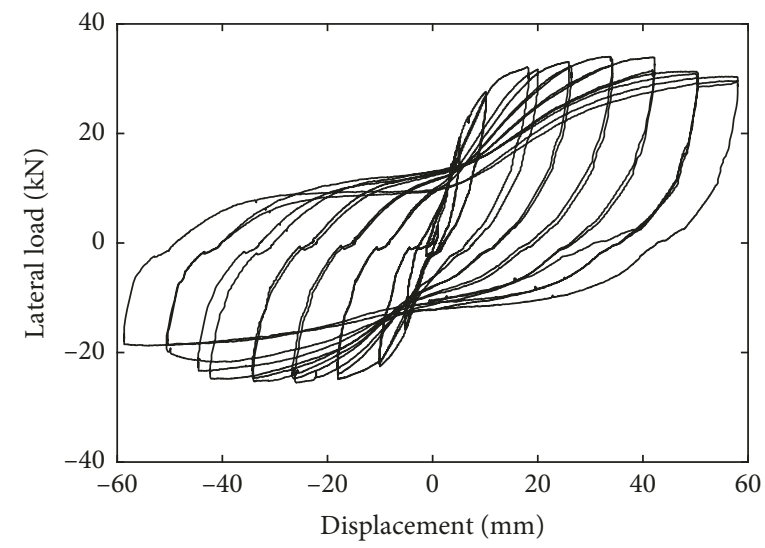

(e)

Figure 6: Tested hysteresis curve of columns: (a) NU-1; (b) NU-2; (c) LU-2; (d) NC-1; (e) NC-2.

the flexural capacity decreases to $85 \%$ of the maximum value, respectively; $l$ is the height of the circular column and equals $1200 \mathrm{~mm}$.

As can be seen in Figure 8 and Table 5, after the steel bars were corroded, the flexural capacity and ductility of the specimen were significantly reduced. It also can be inferred that when the reinforcement ratio decreased, flexural capacity and ductility of columns would decrease too. However, the ultimate flexural capacity and deformation capacity of columns strengthened by BFRP sheets were higher than those of unstrengthened columns. The ultimate flexural capacity and lateral displacement rate of NU-2 were $13.46 \%$ and $38.04 \%$ higher than those of NU-1, respectively. The flexural capacity of LU-2 was strengthened to the flexural capacity level of NU-1, and its ultimate lateral displacement was $22.77 \%$ higher than that of NU-1. The ultimate flexural capacity of NC-2 was increased by $18.71 \%$ compared with NC-1 and recovered to the flexural capacity level of NU-1. The corresponding lateral displacement ratio was increased by $37.25 \%$ compared with NC-1 and $28.07 \%$ compared with 


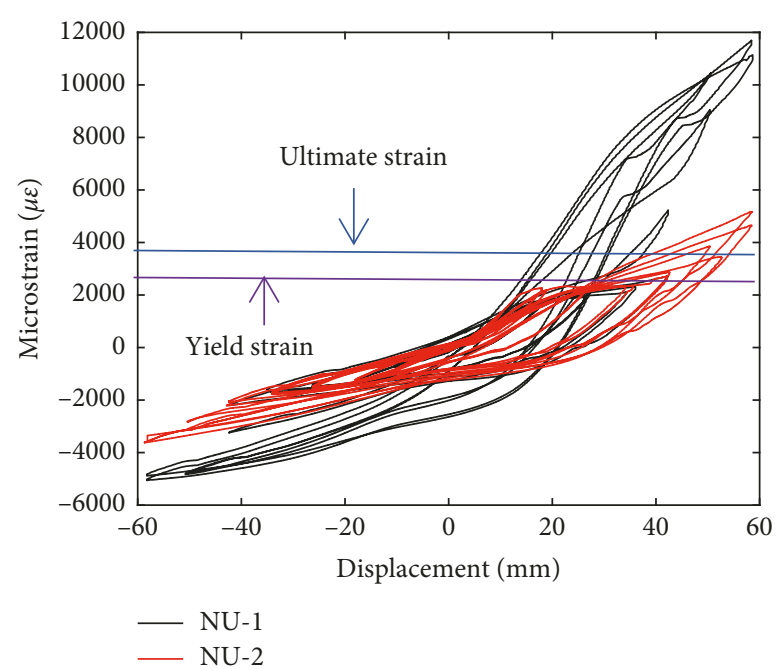

(a)

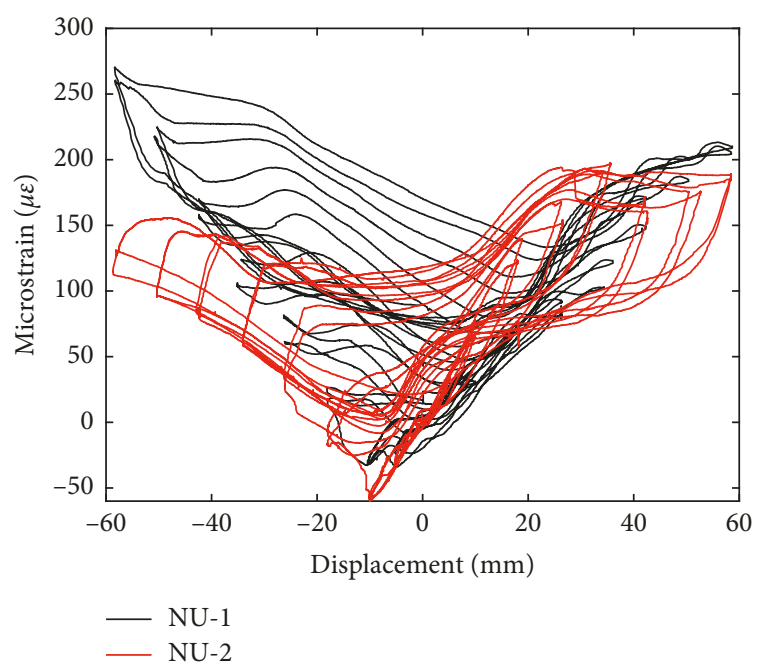

(b)

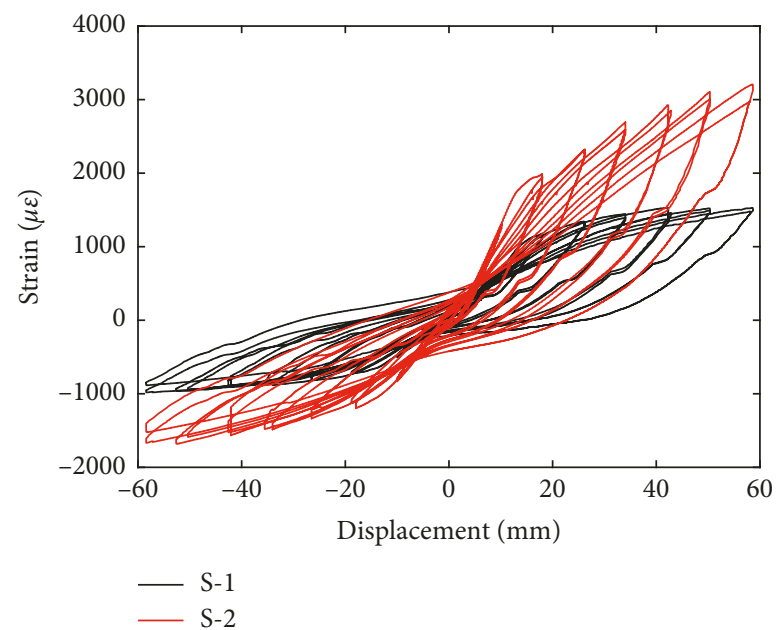

(c)

FIGURE 7: Strain analysis: (a) longitudinal reinforcement; (b) stirrup; (c) BFRP sheet of NU-2.

NU-1. It can be concluded that compared with the unstrengthened columns, BFRP sheets can significantly improve the ductility performance of reinforced concrete columns.

\subsection{Energy Dissipation and Equivalent Viscous Damping} Coefficient. Figure 9(a) shows the energy dissipation process of specimens during cyclic loading. The energy dissipation parameter $E_{\mathrm{D}}$ represents the area of each hysteretic loop of cyclic loading. The cumulative energy dissipation $E_{\mathrm{s}}$ of specimens from initial loading to failure can be predicted by using the following formula and is shown in Figure 9(b):

$$
E_{\mathrm{S}}=\sum_{i=1}^{n} E_{\mathrm{Di}} \text {, }
$$

where $E_{\mathrm{Di}}$ is the energy dissipation of specimens during cyclic loading.

According to Figure 9, reinforcement corrosion reduced the energy dissipation capacity of columns and so did a low reinforcement ratio inevitably. Compared with the specimen NU-1 with a standard reinforcement ratio, the energy dissipation of NU-2 and LU-2 strengthened by BFRP sheets increased by $46.41 \%$ and $16.59 \%$, respectively. Compared with the specimen NC-1, the cumulative energy dissipation of specimen NC-2 increased by $41.82 \%$.

The equivalent viscous damping coefficient $\xi_{\text {eq }}$ also reflects the energy dissipation capacity of columns, which can be calculated by using the following formulas:

$$
\begin{aligned}
\left(E_{\mathrm{e}}\right)_{i} & =\frac{\left|+F_{i}\right|\left|+\Delta_{i}\right|+\left|-F_{i}\right|\left|-\Delta_{i}\right|}{2}, \\
\xi_{\mathrm{eq}} & =\frac{\left(E_{\mathrm{Di}}\right)}{2 \pi\left(E_{\mathrm{e}}\right)_{i}},
\end{aligned}
$$

where $E_{\mathrm{e}}$ is the elastic energy dissipation, and it is the sum of the area of $\mathrm{ABO}$ and $\mathrm{OCD}$ in the triangle in Figure 10; $+F_{i}$ and $-F_{i}$ are the maximum and minimum loading values of the first hysteresis loop during the level of $i$ cyclic loading; and $+\Delta_{i}$ and $-\Delta_{i}$ are corresponding displacement values. 


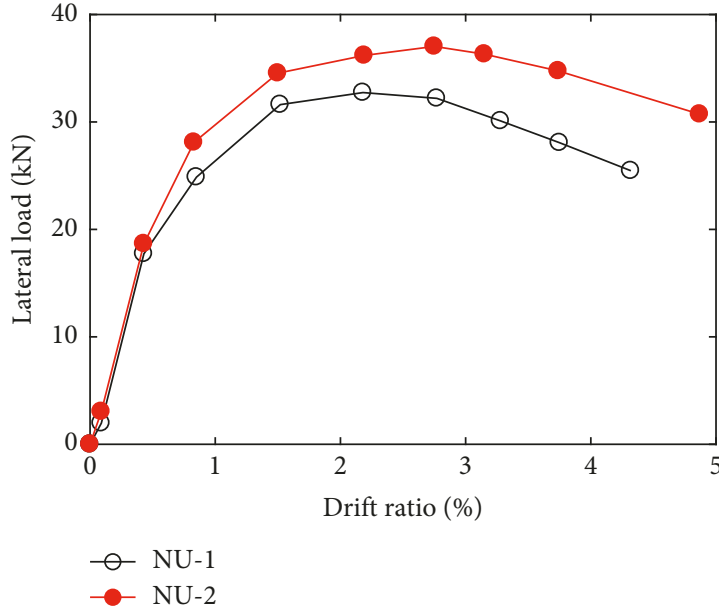

(a)

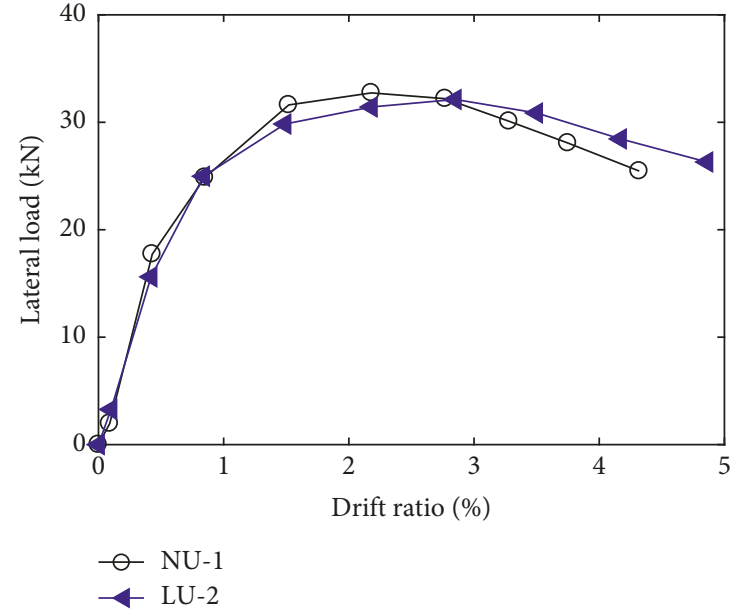

(b)

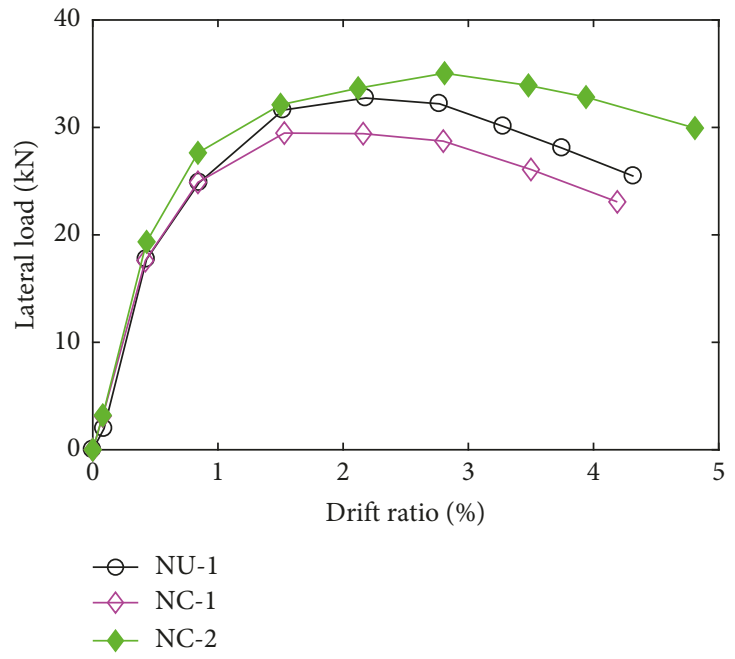

(c)

Figure 8: Column skeleton curve: (a) NU-1and NU-2; (b) NU-1and LU-2; (c) NU-1, NC-1, and NC-2.

TABLE 5: Test result of specimens.

\begin{tabular}{lccccccc}
\hline \multirow{2}{*}{ Specimen } & \multicolumn{2}{c}{ Yield } & \multicolumn{2}{c}{ Peak } & \multicolumn{2}{c}{ Ultimate } & Ductility parameter $\mu$ \\
& $F_{\mathrm{y}}(\mathrm{kN})$ & $\theta_{\mathrm{y}}(\%)$ & $F_{\mathrm{p}}(\mathrm{kN})$ & $\theta_{\mathrm{p}}(\%)$ & $F_{\mathrm{u}}(\mathrm{kN})$ & $\theta_{\mathrm{u}}(\%)$ & 3.47 \\
NU-1 & 26.71 & 1.08 & 32.72 & 2.18 & 27.78 & 3.74 & 4.38 \\
NU-2 & 32.14 & 1.09 & 37.01 & 2.75 & 31.52 & 4.79 & 4.26 \\
LU-2 & 27.01 & 1.03 & 32.13 & 2.85 & 27.31 & 4.36 & 4.16 \\
NC-1 & 24.49 & 0.84 & 29.48 & 1.53 & 25.12 & 3.49 & 4.79 \\
NC-2 & 28.92 & 0.99 & 35.14 & 2.81 & 29.82 & 4.87 \\
\hline
\end{tabular}

Here, the equivalent viscous damping coefficient $\xi_{\text {eq }}$ is calculated by taking the first hysteresis loop of the last loading cycle before column failure, as shown in Table 6 .

The equivalent viscous damping coefficient of NU-2 was $20.00 \%$ higher than that of NU-1, and the equivalent viscous damping coefficient of NC-2 was $9.68 \%$ higher than that of NC-1. BFRP sheets slowed the development of cracks and increased the energy dissipation capacity of columns. At the same time, BFRP sheets also dissipated part of the energy. The equivalent viscous damping coefficients of NC-1 and NC-2 were $3.33 \%$ and $13.33 \%$ higher than those of NU-1, perhaps because rust filled the pores and cracks of concrete and increased the friction between rust and concrete. The equivalent viscous damping coefficient of LU-2 was close to that of NU-1, which indicated that BFRP sheets can improve the equivalent viscous damping coefficient of columns with low reinforcement ratios to the level of columns with standard reinforcement ratios.

3.6. Stiffness Degradation Rule. Because stiffness varies in the loading process, secant stiffness $K_{\mathrm{g} i}$ is usually used to 


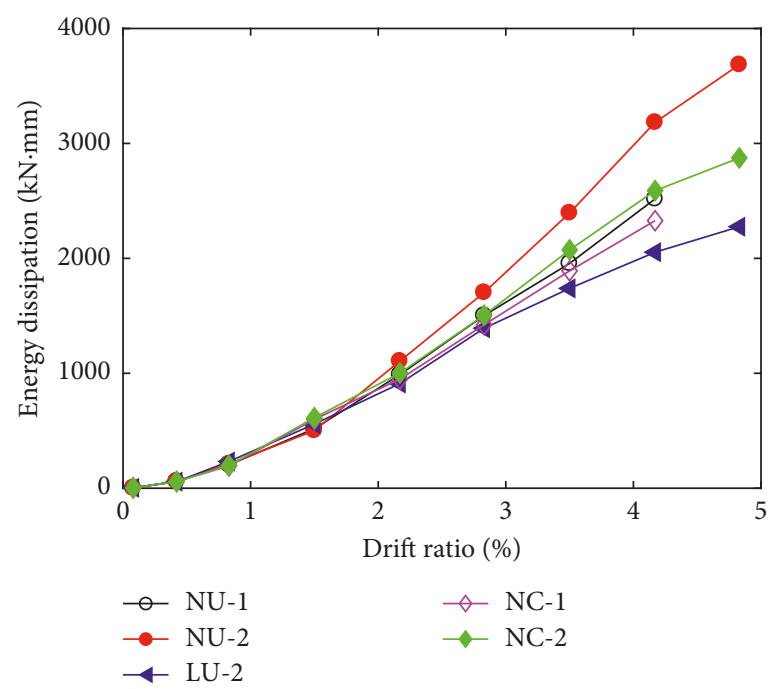

(a)

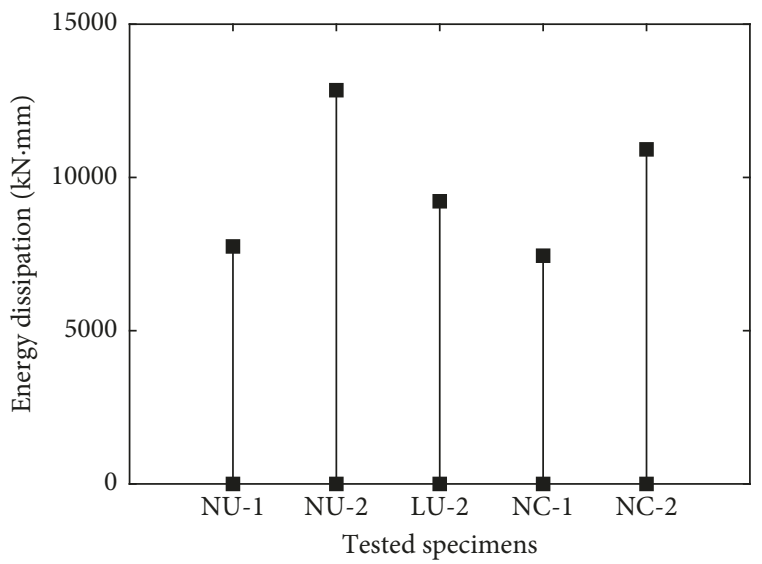

(b)

FIGURE 9: Energy dissipation analysis: (a) energy dissipation $E_{\mathrm{D}}$; (b) cumulative energy dissipation $E_{\mathrm{S}}$.

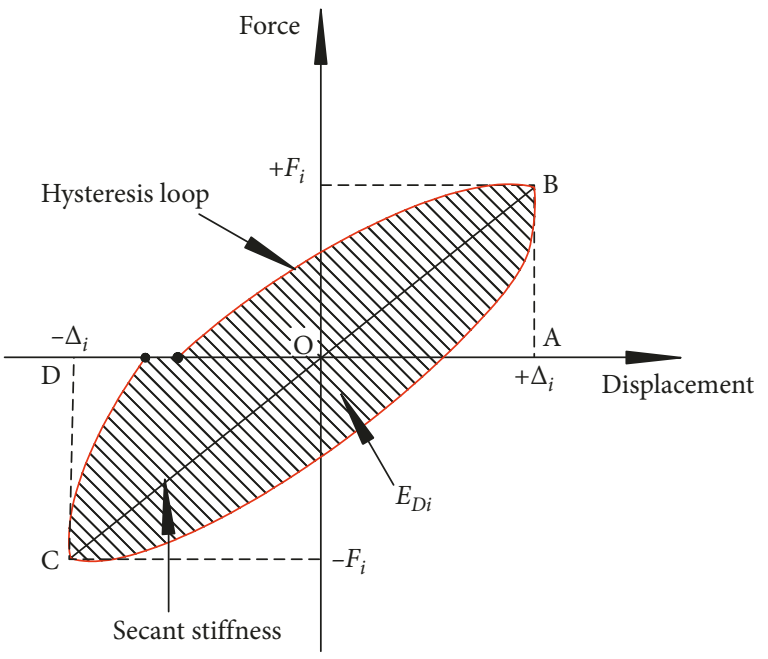

FIGURE 10: Schematic diagram of energy dissipation and secant stiffness.

TABLE 6: Equivalent viscous damping coefficient of specimens.

\begin{tabular}{lccc}
\hline Specimen & Energy dissipation $E_{\mathrm{D}}(\mathrm{kN} \cdot \mathrm{mm})$ & Elastic energy dissipation $E_{\mathrm{e}}(\mathrm{kN} \cdot \mathrm{mm})$ & Equivalent viscous damping ratio $\xi_{\mathrm{eq}}$ \\
\hline NU-1 & 2517.30 & 1327.42 & 0.30 \\
NU-2 & 3685.23 & 1646.62 & 0.36 \\
LU-2 & 2275.50 & 1248.82 & 0.29 \\
NC-1 & 2327.78 & 1178.45 & 0.31 \\
NC-2 & 2973.72 & 1416.84 & 0.34 \\
\hline
\end{tabular}

represent stiffness during seismic response analysis. Secant stiffness can be calculated according to the following formula, and the schematic diagram is shown in Figure 10:

$$
K_{\mathrm{g} i}=\frac{\left|+F_{i}\right|+\left|-F_{i}\right|}{\left|+\Delta_{i}\right|+\left|-\Delta_{i}\right|} .
$$

The stiffness degradation curves of tested specimens are shown in Figure 11.
The stiffness of all specimens decreased along with the increase in lateral displacement. The stiffness degradation rate of NC-1 was higher than that of NU-1, which indicated that reinforcement corrosion would accelerate stiffness degradation. The stiffness degradation curves of LU-2 and NU-1 were basically the same. The stiffness degradation rates of strengthened specimens were lower than those of strengthened ones. Because of the restraining effect of BFRP 


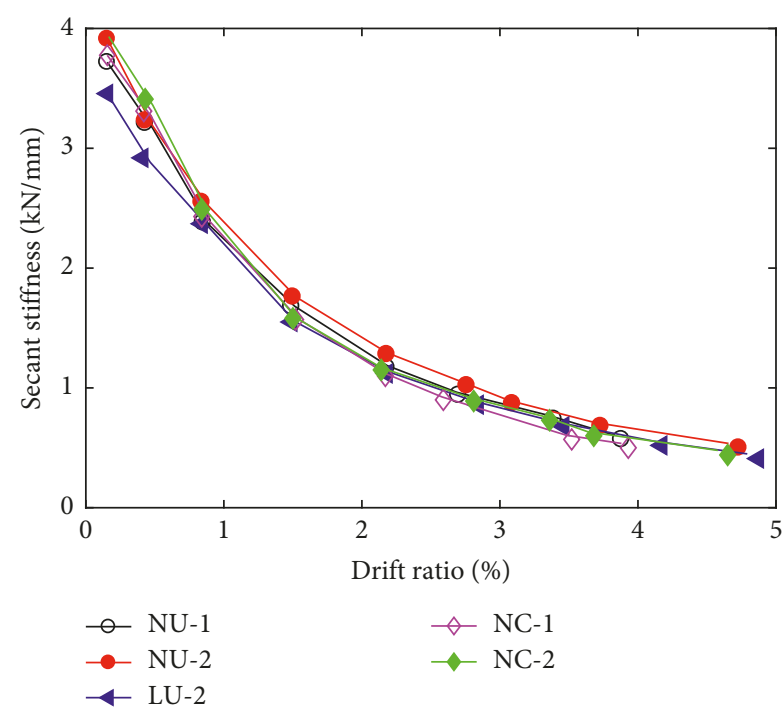

FIgURE 11: Stiffness degradation curves.

sheets, stiffness degradation was delayed and ductility was increased, so that the strengthened columns could still maintain a marginally higher flexural capacity in the case of high deformation and low stiffness in the later loading stage of the tests.

\section{Conclusions}

Comparative quasistatic tests of scaled reinforced concrete pier columns strengthened by BFRP sheets and unstrengthened ones were carried out under constant axial pressure load and lateral reciprocating load. The failure characteristics, hysteretic performance, skeleton curves, energy dissipation, equivalent viscous damping coefficients, and stiffness degradation are compared and analysed.

(1) When the unstrengthened reinforced concrete column was damaged, the concrete on both sides of the plastic hinge area fell off in large quantities, whereas BFRP sheets effectively restrained cracks and crush of concrete in the plastic hinge area.

(2) Under the same conditions, the yield strain and ultimate strain of the strengthened column appeared later than that of the unstrengthened column. Moreover, under the same lateral displacement, the stirrup strain of the strengthened column was lower than that of the unstrengthened column.

(3) Reinforcement ratio and corrosion rate both affected the energy dissipation of reinforced concrete columns. The flexural capacity and ultimate displacement of strengthened specimens were higher than those of the unstrengthened ones. The strengthened specimen with a low reinforcement ratio showed significantly higher ductility and ultimate flexural capacity than the column with standard reinforcement ratio. When the reinforced concrete column was corroded, its flexural capacity and ductility were reduced to a certain extent. However, the lateral load capacity and ductility of the strengthened corroded column were close to those of the uncorroded column.

(4) The ultimate lateral deformation capacity and ductility coefficient of the strengthened columns with standard or low reinforcement ratios and the strengthened corroded specimen were all higher than those of the unstrengthened column with a standard reinforcement ratio.

(5) The energy dissipation capacity of the strengthened corroded column and the column with a low reinforcement ratio was restored to that of the uncorroded column with a standard reinforcement ratio. The stiffness of the column decreased gradually with the increase in lateral displacement, but stiffness degradation rates of strengthened columns were lower than that of unstrengthened ones.

\section{Data Availability}

The data used to support the findings of this study are available from the corresponding author upon request.

\section{Conflicts of Interest}

The authors declare no conflicts of interest.

\section{Acknowledgments}

This study was supported by the Natural Science Foundation of Hebei Education Department in China (Grant No: BJ2018048), Natural Science Foundation of China (Grant No: 51508350 and 51508351), Natural Science Foundation of Hebei Province in China (Grant No: E2016210087), and Graduate Innovation Funding Project of Shijiazhuang Tiedao University in China (Grant No. YC2019008).

\section{References}

[1] X. Li, Z. X. Li, and A. N. Crewe, "Sismic analysis of a high-pier, long-span, continuous RC frame bridge under spatially variable ground motions," Soil Dynamics and Earthquake Engineering, vol. 3, pp. 154-196, 2018.

[2] Ministry of Transport of China, Specification of Seismic Design Highway Engineering, (JTJ 044-89), China Communications Press, Beijing, China, 1990.

[3] Ministry of Transport of China, Guidelines Seismic Design of Highway Bridges, (JTJ 044-89), China Communications Press, Beijing, China, 2008.

[4] National Standardization Administration of China, China Earthquake Parameter Zoning Map (GB 18306-2001), Standard Press of China, Beijing, China, 2002.

[5] P. Zhu, M. Abe, and Y. Fujino, "Modelling three-dimensional non-linear seismic performance of elevated bridges with emphasis on pounding of girders," Earthquake Engineering \& Structural Dynamics, vol. 31, no. 11, pp. 1891-1913, 2002.

[6] J. Hoshikuma, G. F. Zhang, and J. Sakai, "Seismic behavior of retrofit bridges during the 2011 great east Japan earthquake," in Proceedings of the International Symposium on Engineering Lessons Learned from the 2011 Great East Japan Earthquake, Tokyo, Japan, March 2012. 
[7] M. B. Ding, X. C. Chen, and X. Y. Zhang, "Study on seismic strengthening of railway bridge pier with CFRP and concrete jackets," Earthquakes and Structures, vol. 15, pp. 275-283, 2018.

[8] B. Guliz, O. Alpay, and A. Enver, "Seismic performance evaluation and strengthening of a curved bridge having concrete piers and composite deck," Teknik Dergi, vol. 23, pp. 6203-6209, 2012.

[9] J. W. Chen, X. Y. Guo, and X. H. Zheng, "Quasi static experimental study of seismic performance of damaged RC column strengthened with AFL," Journal of Experimental Mechanics, vol. 31, pp. 341-351, 2016.

[10] Y. H. Mugahed Amran, R. Alyousef, R. S. M. Rashid, H. Alabduljabbar, and C.-C. Hung, "Properties and applications of FRP in strengthening RC structures: a review," Structures, vol. 16, pp. 208-238, 2018.

[11] Y. Z. Lin and S. Z. Tian, "Study on influence of CFRP strengthening mode on seismic performance of RC bridge pier," World Earthquake Engineering, vol. 31, pp. 250-259, 2015.

[12] Z. H. Dong, Q. Han, X. L. Du et al., "Experimental study on seismic performance of CFRP confined RC rectangular hollow section bridge piers," in Proceedings of the International Efforts in Lifeline Earthquake Engineering-6th China-Japan-US Trilateral Symposium on Lifeline Earthquake Engineering, Sichuan, China, December 2014.

[13] A. I. Ibrahim, G. Wu, and Z.-Y. Sun, "Experimental study of cyclic behavior of concrete bridge columns reinforced by steel basalt-fiber composite bars and hybrid stirrups," Journal of Composites for Construction, vol. 21, no. 2, article 04016091, 2017.

[14] S. Zhang, L. H. Xu, and X. B. Hu, "Seismic performance of masonry walls strengthened with BFRP," Engineering Journal of Wuhan University, vol. 48, pp. 294-299, 2015.

[15] Y. Y. Zhou, J. T. Yu, and Z. D. Lu, "Seismic behavior of BFRPreinforced pre-damaged concrete beam-column joints," Journal of Central South University of Science and Technology, vol. 41, pp. 1514-1521, 2010.

[16] Y. Y. Zhou, Z. D. Lu, and K. C. Zhang, "Experimental study on seismic behavior of strengthened RC column-beam joints damaged by simulated earthquake," Journal of Building Structures, vol. 31, pp. 64-73, 2010.

[17] J. T. Yu, L. Su, and Z. D. Lu, "Experimental study on BFRP damaged concrete beam-column joints by simulated earthquake," Journal of Tongji University (Natural Science), vol. 39, pp. 18-24, 2011.

[18] G. Wu, Y. Wei, and Z. S. Wu, "Comparative study on seismic performance of rectangular concrete columns strengthened with BFRP and CFRP composites," Industrial Construction, vol. 37, pp. 14-18, 2007.

[19] J. Li, J. Gong, and L. Wang, "Seismic behavior of corrosiondamaged reinforced concrete columns strengthened using combined carbon fiber-reinforced polymer and steel jacket," Construction and Building Materials, vol. 23, no. 7, pp. 2653-2663, 2009.

[20] J. X. Gong and J. B. Li, "Seismic behavior of strengthened corrosion-damaged circular reinforced concrete columns," China Journal of Highway and Transport, vol. 23, pp. 41-48, 2010.

[21] D. Anggawidjaja, T. Ueda, J. Dai, and H. Nakai, "Deformation capacity of RC piers wrapped by new fiber-reinforced polymer with large fracture strain," Cement and Concrete Composites, vol. 28, no. 10, pp. 914-927, 2006.
[22] C. Chisari, C. Bedon, and C. Amadio, "Dynamic and static identification of base-isolated bridges using genetic algorithms," Engineering Structures, vol. 102, no. 11, pp. 80-92, 2015. 


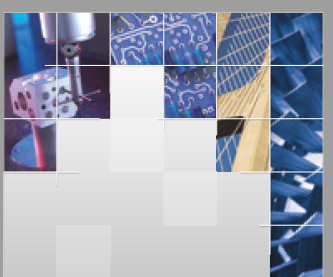

\section{Enfincering}
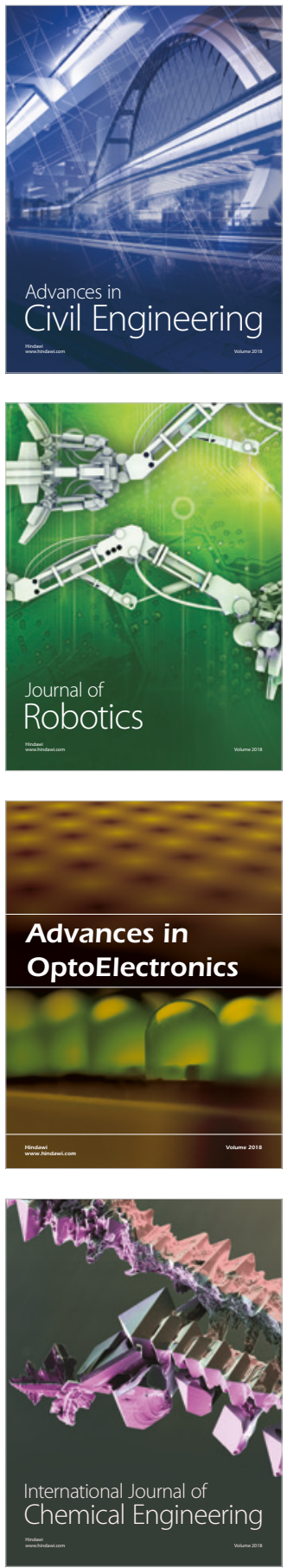

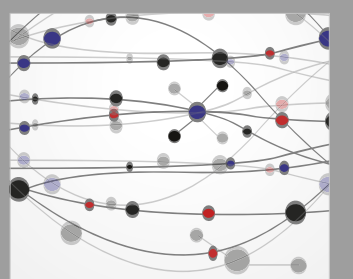

\section{Rotating \\ Machinery}

The Scientific World Journal

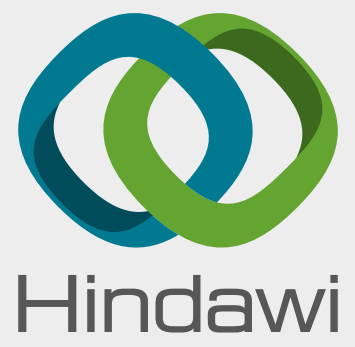

Submit your manuscripts at

www.hindawi.com
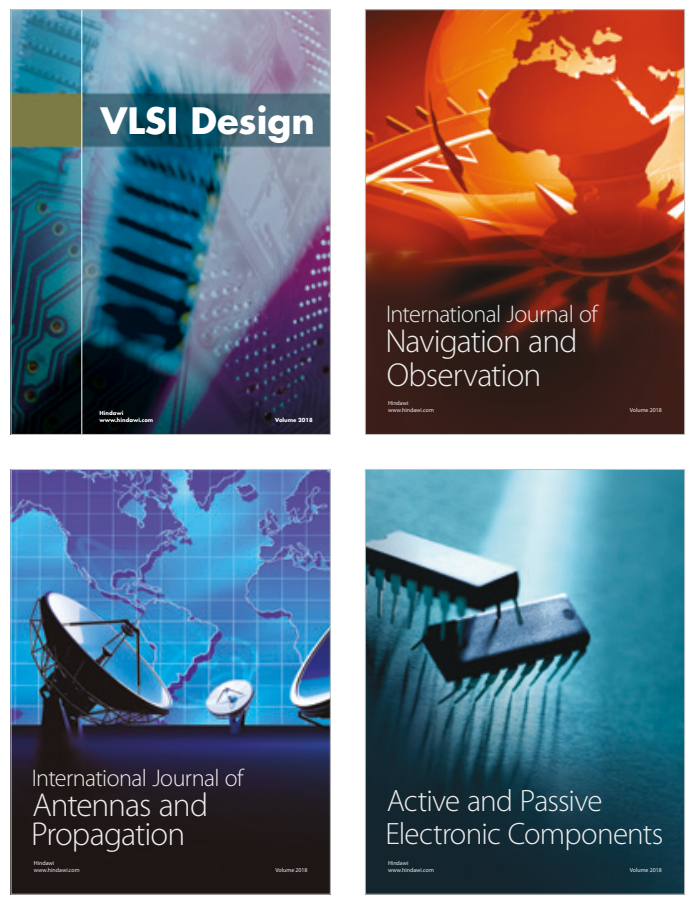
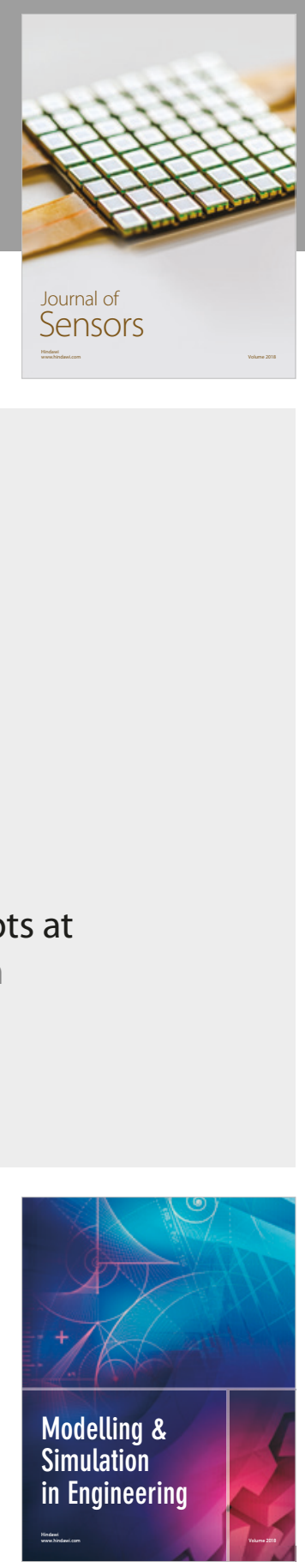

\section{Advances \\ Multimedia}
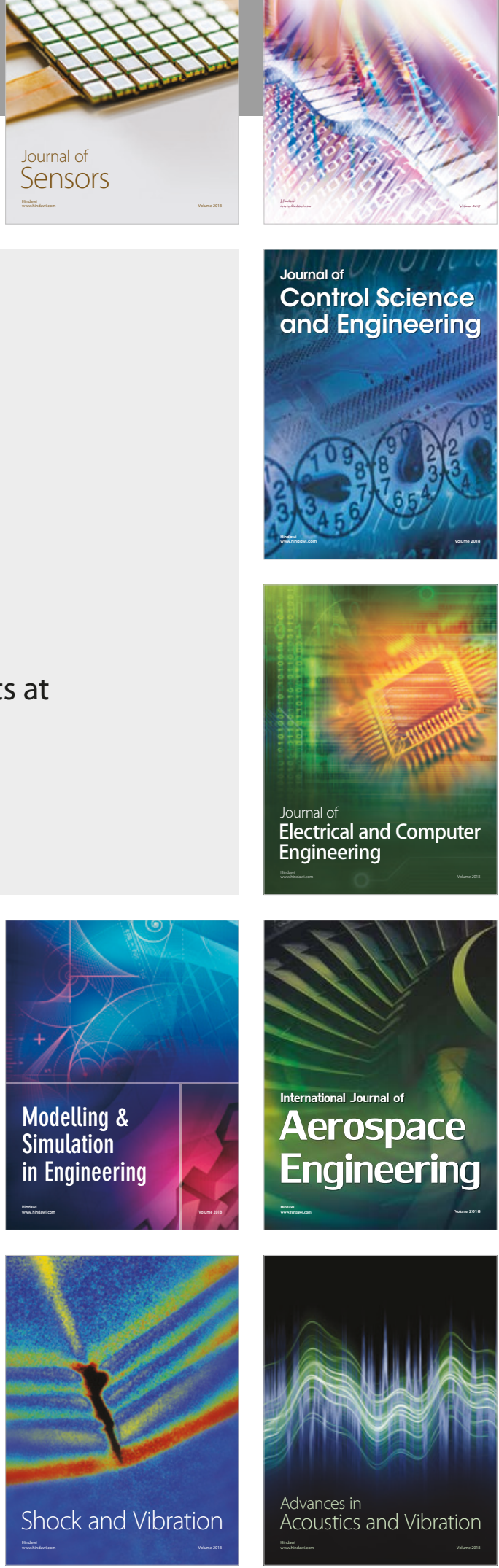